\title{
KEANEKARAGAMAN GULMA DOMINAN PADA PERTANAMAN TOMAT (Lycopersicum esculentum Mill) DI KABUPATEN GARUT
}

\section{THE WEEDS DIVERSITY DOMINANT TO TOMATO (Lycopersicum esculentum Mill) IN GARUT REGENCY}

\author{
Yayan Sumekar $^{1)}$, Jenal Mutakin ${ }^{2)}$, Yussi Rabbani' ${ }^{2)}$ \\ 1) Departemen Budidaya Pertanian Fakultas Pertanian Universitas Padjadjaran \\ ${ }^{2)}$ Fakultas Pertanian Universitas Garut \\ E-mail : yayan.sumekar@gmail.com
}

\begin{abstract}
ABSTRAK
Penelitian ini bertujuan untuk membuat pemetaan gulma-gulma pada pertanaman tomat di Kabupaten Garut. Penelitian ini menggunakan metode penelitian deskriptif, melalui metode survey. Setiap komoditas pertanaman diteliti pada 4 areal yang menyebar di berbagai kondisi lingkungan yang berbeda dengan umur tanaman berkisar 25 sampai 40 hari. Setelah didapatkan jumlah petak-contoh yang diperlukan maka dilakukan analisis vegetasi. Setiap analisis vegetasi ditentukan : spesies gulma, kerapatan gulma, frekuensi gulma, dominasi gulma, SDR, koefisien komunitas, bobot kering gulma. Kuesioner diberikan kepada petani untuk mengetahui sejarah daerah penelitian, seperti varietas tanam yang digunakan, pola tanam yang digunakan, jenis pupuk yang digunakan, teknik pengendalian gulma, dan usia tanaman.

Hasil penelitian menunjukkan gulma dominan yang ditemukan di areal tanaman tomat 16 spesies gulma. Tercatat 11 spesies gulma daun lebar, yaitu : Alteranthera sessilis, Oxalis latifolia, Portulaca oleraceae, Erechtites valerianifolia, Drymaria villosa, Amaranthus spinonsus, Galinsoga parviflora, Erigeron sumatrensis, Oxalis corniculata, Ageratum conyzoides, dan Richardia brasiliensis. Tercatat 4 spesies gulma rumput, yaitu: Digitaria cilaris, Eulesine indica, Cynodone dactilone, dan Leptochloa chinensis. Terdapat 1 spesies gulma teki, yaitu: Cyperus rotundus.
\end{abstract}

Kata Kunci : Keanekaragaman, Gulma, Tomat 


\begin{abstract}
The purpose of this study was to map of tomato crop ini Garut Regency. This applied descriptive method by survey technique. Research object was tomato and carrot crops ranged from 25 to 40 days in 4 planted field of various environmental conditions. Having obtained the necessary plot-examples, vegetation analysis could be perfomed. Any anylisis of vegetation will be determined: all weed species, weed density, weeds frequency, weed dominance, $S D R$, the coefficient of community, the dry weight of weeds. The questionnaire was given to the farmer to find out the history of the studied area of tomato and carrot, such as crop varieties, cropping patterns used, kind of fertilizer used, weed control technique, and age of crop.

The results showed that the dominant weeds species that found in tomato plantations were 16. There are eleven broad leaves weeds : Alteranthera sessilis, Oxalis latifolia, Portulaca oleraceae, Erechtites valerianifolia, Drymaria villosa, Amaranthus spinonsus, Galinsoga parviflora, Erigeron sumatrensis, Oxalis corniculata, Ageratum conyzoides, and Richardia brasiliensis. Four types of grass weeds : Digitaria cilaris, Eulesine indica, Cynodone dactilone, and Leptochloa chinensis. One type weed: Cyperus rotundus.
\end{abstract}

Keywords : Diversity, Weeds, Tomato

\title{
PENDAHULUAN
}

Gulma merupakan tumbuhan lain yang tumbuh dipertanaman budidaya yang sedang diusahakan, yang keberadaannya tidak dikehendaki oleh manusia dan mempunyai dampak negatif bagi tanaman budidaya. Pengaruh negatif yang ditimbulkan oleh kehadiran gulma terhadap tanaman pertanian, adalah (1) gulma mempunyai daya kompetitif akan ruang, hara, dan cahaya, (2) beberapa gulma merupakan tumbuhan inang bagi hama dan penyakit tanaman, (3) dapat mengurangi mutu hasil pertanian, karena mengotori, menurunkan kemurnian hasil, ataupun memberikan rasa dan bau yang tidak asli, dan (4) dapat menghambat kelancaran aktivitas pertanian (Sastroutomo, 1990).

Tanaman tomat (Lycopersium escuslentum Mill) adalah tumbuhan berbentuk perdu atau semak dan termasuk ke dalam golongan tanaman berbunga (Angiospermai). Tanaman tomat termasuk tanaman sayuran yang sudah dikenal sejak dahulu. Peranannya yang penting dalam pemenuhan gizi masyarakat sudah sejak lama diketahui orang. Menurut Direktotat Jenderal Hortikultura (2015) di Indonesia, luas lahan tomat pada tahun 2013 adalah $59.758 \mathrm{Ha}$ dan pada tahun 2014 adalah 59.008 Ha. Produksi tomat tahun 2013 adalah 992.780 ton dan tahun 2014 sebanyak 915.987 ton. Berdasarkan data tersebut, terjadi penurunan dari 
tahun 2013 ke tahun 2014 yaitu menurun sekitar 7,74\%. Pada tahun 2014 tanaman tomat hanya dapat berkontribusi terhadap produksi sayuran di Indonesia sebesar 7,69 ton. Kebutuhan konsumen akan tomat dikhawatirkan masih belum bisa diimbangi dengan produksi tomat per tahun.

Keadaan agroklimat di Garut yang cocok untuk wortel akan berdampak positif terhadap peningkatan pendapatan petani, perbaikan gizi masyarakat, perluasan kesempatan kerja, pengembangan agribisnis, pengurangan impor, dan peningkatan ekspor. Karakteristik topografi Kabupaten Garut sebelah Utara terdiri dari dataran tinggi dan pegunungan. Wilayah yang paling rendah sejajar dengan permukaan laut, hingga wilayah tertinggi di puncak gunung. Ketinggian 100 sampai 1500 m dpl terdapat di Kecamatan Cisurupan dan Kecamatan Pasirwangi. Kecamatan Cisurupan berada pada ketinggian 1000 sampai $1300 \mathrm{~m}$ dpl dan Kecamatan Pasirwangi berada pada ketinggian 925 sampai 1450 m dpl merupakan ketinggian yang cocok untuk ditanami tomat yang dapat tumbuh baik di dataran rendah maupun tinggi, serta tanaman wortel yang cocok pada ketinggian 600 sampai 1200 m dpl (Badan Pusat Statistik, 2016). Secara umum iklim di Kabupaten Garut dikategorikan sebagai daerah beriklim tropis basah, sesuai dengan karakteristik tersebut peran sektor pertanian masih merupakan sektor andalan.

Kendala dalam meningkatkan hasil wortel dan tomat yaitu gulma. Gulma dapat dikendalikan dengan beberapa cara, antara lain secara mekanis, kultur teknis, biologis kimia, dan terpadu. Pengendalian secara kimiawi yang diformulasikan atas dasar fisiologis tumbuhan untuk mematikan gulma-gulma tertentu. Penggunaan herbisida di lapangan efektif dalam mengendalikan gulma mulai dari saat tanam sampai menjelang panen. Menurut Tjitrosoedirdjo dan Utomo (1984), pengendalian gulma dengan herbisida hanya memerlukan 3 sampai 4 hari orang kerja $(\mathrm{HOK}) /$ ha lebih rendah bila dibandingkan dengan penyiangan secara manual yang memerlukan 35 sampai $40 \mathrm{HOK} / \mathrm{ha}$, keuntungan lain yaitu jenis gulma tertentu yang peka akan mati, efesien waktu, dan hemat biaya karena herbisida diberikan hanya satu kali.

Keragaman gulma merupakan unsur yang sangat penting dalam menentukan langkah pengendalian gulma pada suatu areal pertanaman budidaya. Keragaman gulma di suatu pertanaman budidaya dipengaruhi berbagai faktor, seperti cahaya, unsur hara, dan cara budidaya mengikuti kaidah umum dinamika populasi tumbuhan. Jenis tanah dan jenis tanaman yang dibudidayakan mempengaruhi jumlah dan keanekaragaman jenis gulma (Knott, 2002). Spesies gulma juga dipengaruhi oleh kerapatan tanaman, kesuburan tanah, pola budidaya dan pengolahan tanah (Aldrich dan Kremer, 1997). Sedangkan menurut Nasution (1981) faktor yang mempengaruhi keragaman komunitas gulma yaitu ketinggian tempat di atas permukaan laut.

Teknis pengendalian gulma pada pertanaman tomat yang efektif dan efisien memerlukan informasi tentang keragaman gulma yang ada, sehingga perlu 
dilakukan penelitian tentang "Keanekaragaman Gulma Dominasi Tanaman Tomat di Kabupaten Garut".

\section{METODOLOGI}

\section{Lokasi dan Waktu Penelitian}

Percobaan ini dilaksanakan di areal pertanaman hortikultura milik petani di wilayah Kabupaten Garut di 2 kecamatan dengan masing-masing 2 desa yaitu Kecamatan Cisurupan di Desa Cisurupan dan Desa Kramatwangi, serta Kecamatan Pasirwangi di Desa Padawas dan Desa Barusari. Lokasi percobaan berada pada berbagai jenis lokasi dan budidaya sebelumnya yang berbeda. Percobaan ini dimulai pada bulan September sampai November 2016.

\section{Bahan dan Alat Penelitian}

Bahan yang digunakan adalah pada percobaan ini adalah vegetasi gulma di empat areal pertanaman sayuran tomat di Kabupaten Garut, dan kuesioner bahan penelitian.

Alat yang digunakan adalah frame $0,5 \times 0,5 \mathrm{~m}$, gunting, oven, timbangan analitik, kertas, amplop, plastik, cemi, pensil/pulpen, dan buku.

\section{Metode Penelitian}

Metode yang digunakan mencakup kualitatif (weed survey) dan kuantitatif (identifikasi). Terdapat empat lokasi areal tanaman hortikultura dengan jenis tanaman wortel secara acak sebagai sampel. Setiap lokasi sampel dilakukan analisis vegetasi gulma secara diagonal ( 5 kali) untuk setiap luasan lahan pertanaman wortel dengan metode kuadrat, ukuran kuadran yang digunakan $0,5 \mathrm{~m}$ x 0,5 m. Analisis data dilakukan analisis kuantitatif untuk mengetahui indeks keanekaragaman $(\mathrm{H})$ berdasarkan Shannon-Wiener.

\section{RANCANGAN RESPON}

Analisa vegetasi adalah cara mempelajari susunan (komposisi jenis) dan bentuk (struktur) vegetasi atau masyarakat tumbuh-tumbuhan (Soerianegara, 2005). Analisis vegetasi gulma dilakukan dengan mengambil gulma dari petak destruktif $1 \mathrm{~m}^{2}$ dan dikelompokan per spesies gulma. Bobot kering per spesies dan total diukur dengan cara menimbang gulma yang telah dikeringkan dalam oven sampai mencapai bobot konstan pada suhu $80^{\circ} \mathrm{C}$. selanjutnya penghitungan nilai penting gulma (NP), nilai jumlah dominasi gulma (NJD), indeks keragaman gulma, indeks dominasi (D) jenis gulma dan indeks dominasi spesies gulma (D) dengan rumus sebagai berikut : 
a) Nilai Penting Gulma (NP) adalah nilai yang diperoleh dari perhitungan sebagaimana dikemukakan oleh Chaves dan Bhandari (1982) yaitu

$$
\begin{aligned}
\text { Kerapatan relatif suatu jenis }= & \frac{\text { nilai kerapatan mutlak satu golongan }}{\sum \text { nilai kerapatan mutlak semua golongan }} \times 100 \% \\
\text { Frekuensi relatif suatu jenis }=\frac{\text { nilai frekuensi mutlak satu golongan }}{\sum \text { nilai frekuensi mutlak semua golongan }} \times 100 \% & \text { nilai dominasi mutlak satu golongan } \\
\text { Dominasi relatif suatu jenis } & =100 \%
\end{aligned}
$$

Nilai penting $(\mathrm{NP})=$ Kerapatan relatif + Frekuensi Relatif + Dominasi relatif

b) Nilai Jumlah Dominasi (NJD) berguna untuk menggambarkan hubungan jumlah dominansi suatu jenis gulma dengan jenis gulma lainnya dalam suatu komunitas.

$$
N J D=\frac{\text { nilai penting }}{3}
$$

Jenis gulma yang mempunyai nilai NJD terbesar berarti gulma tersebut merupakan gulma dominan.

c) Bobot kering gulma per spesies, pengamatan dilakukan pada saat analisa vegetasi dengan mengambil dari petak destruktif $0,5 \mathrm{~m}^{2}$ dan dikelompokkan ke dalam tiga golongan gulma, yaitu berdaun lebar, rerumputan, dan teki. Bobot kering diukur dengan cara menimbang gulma yang telah dikeringkan dalam oven hingga mencapai bobot konstan pada suhu 800C.

d) Koefisien komunitas menurut Tjitrosoedirdjo $d k k$ (1984), dapat dihitung dengan rumus sebagai berikut:

$$
C=\frac{2 W}{a+b} \times 100 \%
$$

Keterangan:

$\mathrm{W}$ : Jumlah dari dua kuantitas terendah untuk jenis dari masing-masing komunitas

a : Jumlah dari seluruh kuantitas pada komunitas pertama

b : Jumlah dari seluruh kuantitas pada komunitas kedua

e) Mengetahui besarnya Indeks Keanekaragaman Spesies (H') pada suatu komunitas dengan menggunakan rumus menurut Barbour, Burk and Pitts (1987). Data diolah menggunakan Program Ecological Methodology $2^{\text {nd }}$ edition (Krebs,2000).

$$
H^{\prime}=-\sum_{i=1}^{0}(p i)(\operatorname{In} p i)
$$

Dimana $:$ pi $=$ ni $/ \mathrm{N}$

$\mathrm{ni}=$ jumlah nilai penting suatu spesies 
$\mathrm{N}=$ jumlah nilai penting seluruh spesies

In = logaritme natural

Agar nilai Indeks Keanekaragaman spesies (H') Shannon-Wiever dapat ditafsirkan maknanya maka digunakan kriteria menurut Barbour, Burk and Pitts (1987); Djufri (2003). Nilai H' biasanya berkisar dari 0 sampai 7. Jika H' $<1$ kategori sangat rendah, jika H'> 1 sampai 2 kategori rendah, jika H'> 2 sampai 3 kategori sedang (medium), jika $\mathrm{H}^{\prime}>3$ sampai 4 kategori tinggi dan jika $\mathrm{H}^{\prime}>4$ kategori sangat tinggi.

\section{HASIL DAN PEMBAHASAN}

\section{Nilai Penting Gulma}

Hasil yang terdapat pada Tabel 1 menunjukkan bahwa spesies gulma yang terdapat pada tanaman tomat di Kecamatan Cisurupan ada 16 spesies gulma. Tercatat 11 spesies gulma daun lebar, yaitu : Alteranthera sessilis, Oxalis latifolia, Portulaca oleraceae, Erechtites valerianifolia, Drymaria villosa, Amaranthus spinonsus, Galinsoga parviflora, Erigeron sumatrensis, Oxalis corniculata, Ageratum conyzoides, dan Richardia brasiliensis. Tercatat 4 spesies gulma daun sempit, yaitu : Digitaria cilaris, Eulesine indica, Cynodone dactilone, dan Leptochloa chinensis. Terdapat 1 spesies gulma teki, yaitu: Cyperus rotundus.

Data pada Tabel 1 menunjukkan bahwa spesies gulma yang terdapat pada tanaman tomat di Kecamatan Pasirwangi ada 16 spesies gulma. Tercatat 11 spesies gulma daun lebar, yaitu : Alteranthera sessilis, Oxalis latifolia, Portulaca oleraceae, Erechtites valerianifolia, Drymaria villosa, Amaranthus spinonsus, Galinsoga parviflora, Erigeron sumatrensis, Oxalis corniculata, Ageratum conyzoides, dan Richardia brasiliensis. Tercatat 4 spesies gulma daun sempit, yaitu: Digitaria cilaris, Eulesine indica, Cynodone dactilone, dan Leptochloa chinensis. Terdapat 1 spesies gulma teki, yaitu: Cyperus rotundus. Sedangkan nilai penting gulma yang tinggi pada tanaman tomat di Kecamatan Cisurupan ditunjukkan oleh golongan gulma daun lebar seperti Galinsoga parviflora. Nilai pening yang rendah ditunjukkan oleh golongan gulma daun lebar yaitu, Richardia brasiliensis.

Data pada Tabel 1 menunjukkan bahwa nilai penting yang tinggi pada tanaman tomat di Kecamatan Pasirwangi ditunjukkan oleh golongan gulma daun lebar seperti Galinsoga parviflora. Nilai pening yang rendah ditunjukkan oleh golongan gulma daun lebar yaitu, Erigeron sumatrensis.

Pada data tersebut terlihat bahwa populasi gulma pada tanaman tomat di Kabupaten Garut didominasi oleh spesies-spesies gulma berdaun lebar, ini disebabkan gulma daun lebar memiliki daya kompetisi terhadap penyerapan cahaya lebih tinggi dibanding dengan jenis gulma teki selain. Jenis gulma berdaun lebar 
umumnya mampu menghasilkan jumlah biji yang berlimpah sehingga sulit untuk dikendalikan.

Pada areal tomat Famili Asteraceae yaitu Galinsoga parviflora merupakan jenis yang memiliki jumlah individu terbanyak karena faktor lingkungan dan perkembangbiakannya mendukung. Menurut Reader and Buck (2000), gulma famili Asteraceae dapat berkembang biak melalui biji, mempunyai kemampuan beradaptasi dengan lingkungan, misalnya sedikit air sampai tempat basah dan tahan terhadap naungan. Kebutuhan akan cahaya, temperatur, air dan ruang tumbuh terpenuhi, sehingga gulma ini dapat berkembang cepat.

Tabel 1. Nilai Penting Gulma pada Tanaman Tomat di Kabupaten Garut

\begin{tabular}{ccccc}
\hline & & & \multicolumn{2}{c}{ Nilai Penting (\%) } \\
\cline { 4 - 5 } No & Gulma & Nama Lokal & $\begin{array}{c}\text { Kec. } \\
\text { Cisurupan }\end{array}$ & $\begin{array}{c}\text { Kec. } \\
\text { Pasirwangi }\end{array}$ \\
\hline 1 & & Kremah & 29,24 & 11,57 \\
2 & Oxalis latifolia & Calincing & 48,43 & 22,31 \\
3 & Portulaca oleraceae & Krokot & 13,26 & 12,84 \\
4 & Erechhites valerianifolia & Sintrong & 6,46 & 6,95 \\
5 & Ageratum conyzoides & Wedusan & 7,33 & 14,46 \\
6 & Drymaria villosa & Selaton & 12,07 & 19,47 \\
7 & Digitaria cilaris & Rumput Kebo & 11,26 & 15,68 \\
8 & Eulisine indica & Carulang & 33,36 & 40,18 \\
9 & Amaranthus spinonsus & Bayam Duri & 18,03 & 26,91 \\
10 & Cyperus rotundus & Teki & 18,41 & 21,23 \\
11 & Galinsoga parviflora & Kuningan & $\mathbf{4 9 , 4 6}$ & $\mathbf{7 6 , 8 6}$ \\
12 & Erigeron sumatrensis & Jabung & 10,49 & 2,69 \\
13 & Cynodone dactilone & Grintingan & 26,82 & 4,86 \\
14 & Richardia brasiliensis & Goletrak beuti & 1,68 & 8,65 \\
15 & Oxalis corniculata & Cacalincingan & 10,80 & 6,79 \\
16 & Leptochloa chinensis & Bobotengan & 2,92 & 8,57 \\
\hline
\end{tabular}

\section{Nilai Jumlah Dominasi (NJD)}

Data pada Tabel 2 menunjukkan bahwa spesies gulma dominan yang ditemukan di areal percobaan tanaman tomat di Kecamatan Cisurupan dan Kecamatan Pasirwangi ada 5 spesies, tercatat 3 spesies gulma berdaun lebar : Galinsoga parviflora, Alteranthera sessilis, dan Oxalis latifolia, 2 spesies gulma daun sempit: Eulesine indica dan Cynodone dactilone. Hal ini menunjukkan bahwa gulma dominan pada tanaman tomat di Kabupaten Garut bervariasi, tetapi umumnya didominasi oleh gulma daun lebar. Galinsoga parviflora merupakan gulma daun lebar yang paling dominan dan ditemukan di semua desa areal percobaan tanaman tomat di Kabupaten Garut. 
Banyak faktor yang mempengaruhi keragaman komunitas gulma diantaranya yaitu pola tanam, dan cara pengendalian gulma yang berbeda. Gulma spesies tertentu secara ekologis dapat tumbuh dengan baik pada daerah budidaya dengan jenis tanaman tertentu dan mendominasi daerah pertanaman budidaya. Pergiliran tanaman secara ekologis dapat mencegah adanya dominasi spesies gulma atau kelompok gulma tertentu pada daerah pertanaman budidaya.

Pola tanam berpengaruh terhadap komposisi gulma. Pada monokultur dalam waktu yang lama menunjukkan komposisi gulma yang lebih rendah dibandingkan dengan pola tanam rotasi. Menurut Mahfudz, et al. (2005) perubahan pola tanam dari monokultur, tumpangsari hingga menjadi monokultur menyebabkan jumlah jenis gulma berkurang dan komunitas gulma cenderung berubah. Perubahan pola tanam juga merubah komposisi jenis gulma dominan, dari jenis gulma berdaun lebar digantikan oleh gulma golongan rerumputan. Selain perubahan komposisi tersebut, pola tanam juga menyebabkan penekanan jenis gulma dominan. Gulma Galinsoga parviflora dan Portulaca oleracea merupakan gulma dominan pada pertanaman tomat terus menerus, sedangkan hanya gulma Galinsoga parviflora merupakan gulma dominan pada rotasi tomat-petsai.

Tabel 2. Gulma Dominan Tanaman Tomat di Empat Lahan Kabupaten Garut

\begin{tabular}{|c|c|c|c|c|c|}
\hline \multirow{2}{*}{ No } & \multirow{2}{*}{ Spesies } & \multicolumn{4}{|c|}{ Summed Dominance Ratio (SDR) \% } \\
\hline & & 1 & 2 & 3 & 4 \\
\hline 1. & Eulesine indica & 14,06 & & 17,35 & 10,38 \\
\hline 2. & Galinsoga parviflora & 19,23 & 13,38 & 26,63 & 24,34 \\
\hline 3. & Cynodone dactilone & 12,36 & & & \\
\hline 4. & Alteranthera sessilis & & 12,36 & & \\
\hline \multirow[t]{3}{*}{5.} & Oxalis latifolia & & 34,63 & & \\
\hline & Spesies gulma lain & 54,35 & 39,63 & 56,02 & 65,68 \\
\hline & Total & 100 & 100 & 100 & 100 \\
\hline
\end{tabular}

Keterangan : Gulma yang memiliki persentase diatas $10 \%$

1 = Desa Cisurupan, 2 = Desa Kramatwangi, 3 = Desa Padaawas, $4=$ Desa Barusari.

Pengendalian gulma di Kecamatan Cisurupan menggunakan herbisida dan tidak diikuti dengan penyiangan kembali, sedangkan di Kecamatan Pasirwangi menggunakan herbisida dan diikuti dengan penyiangan. Konsep penggunaan herbisida perlu memenuhi kriteria sedikit, selektif, sistemik dan security (keamanan). Herbisida dalam jumlah sedikit efektif menghambat atau mematikan gulma. Herbisida juga harus selektif mematikan gulma dan tanaman terhindar dari efek merugikan. Herbisida juga dimungkinkan untuk dapat masuk dalam sistem jaringan gulma dan mematikan gulma. Herbisida juga harus aman terhadap pemakai 
atau penyemprot dan lingkungan Pemakaian herbisida dalam jangka panjang perlu mempertimbangkan kemungkinan resistensi gulma terhadap aplikasi herbisida. Gulma menjadi lebih tahan terhadap penyemprotan herbisida karena dilakukan berulang-ulang dalam jangka waktu lama dengan menggunakan suatu jenis herbisida yang sama.

Penyiangan gulma merupakan tindakan pengelolaan gulma yang bertujuan untuk mengurangi/menghilangkan adanya kompetisi antara gulma dengan tanaman. Penyiangan gulma dapat dilihat sebagai tindakan pencegahan maupun tindakan pengendalian gulma. Penyiangan gulma didasarkan pada fase pertumbuhan gulma. Penyiangan yang dilakukan sebelum gulma memasuki fase generatif dapat mencegah perkembangan dan penyebaran gulma melalui biji dan juga mencegah penambahan biji gulma di dalam tanah (seed bank).

Dilihat dari fase perkembangan tanaman budidaya, gulma tidak harus dikendalikan sepanjang periode pertumbuhan tanaman budidaya. Nietto et al. (1968) menyatakan bahwa kehadiran gulma di sepanjang siklus hidup tanaman tidak selalu berpengaruh negatif terhadap produksi tanaman. Terdapat fase dimana tanaman budidaya sensitif terhadap keberadaan gulma dan keberadaan gulma pada fase tersebut dapat menurunkan hasil secara nyata, disebut sebagai periode kritis. Pada periode kritis tersebut gulma perlu dikendalikan agar tidak terjadi kompetisi yang dapat menyebabkan penurunan produktivitas tanaman.

\section{Bobot Kering Gulma per Spesies}

Pengamatan dilakukan pada saat analisa vegetasi dengan mengambil dari petak destruktif $0,5 \mathrm{~m}^{2}$ dan dikelompokkan ke dalam tiga golongan gulma, yaitu berdaun lebar, rerumputan, dan teki. Bobot kering diukur dengan cara menimbang gulma yang telah dikeringkan dalam oven hingga mencapai bobot konstan pada suhu $80^{\circ} \mathrm{C}$.

Spesies gulma yang memiliki bobot kering paling tinggi pada tanaman tomat di Kecamatan Cisurupan adalah Alteranthera sessilis. Sedangkan spesies gulma yang memiliki bobot kering paling tinggi pada tanaman tomat di Kecamatan Pasirwangi adalah Galinsoga parviflora. Bobot kering gulma total pada tanaman tomat di Kecamatan Cisurupan adalah 210,71 gram, sedangkan bobot kering gulma total pada tanaman wortel adalah 205,87 gram.

Spesies gulma yang memiliki bobot kering paling tinggi pada tanaman tomat pada Tabel 3 di Kecamatan Cisurupan adalah Alteranthera sessilis. Sedangkan spesies gulma yang memiliki bobot kering paling tinggi pada tanaman tomat di Kecamatan Pasirwangi adalah Galinsoga parviflora. Bobot kering gulma total pada tanaman tomat di Kecamatan Cisurupan adalah 210,71 gram, sedangkan bobot kering gulma total pada tanaman wortel adalah 205,87 gram. 
Tabel 3. Bobot Kering Gulma per Spesies dan Total pada Tanaman Tomat di Kabupaten Garut

\begin{tabular}{cccc}
\hline \multirow{2}{*}{ No } & \multirow{2}{*}{ Gulma } & \multicolumn{2}{c}{ Bobot Kering Gulma $(\mathbf{g})$} \\
\cline { 3 - 4 } & & Kec. Cisurupan & Kec. Pasirwangi \\
\hline 1 & Alteranthera sessilis & 32,18 & 0,41 \\
2 & Oxalis latifolia & 12,57 & 2,94 \\
3 & Portulaca oleraceae & 13,43 & 17,87 \\
4 & Erechhites valerianifolia & 1,19 & 4,21 \\
5 & Ageratum conyzoides & 6,40 & 10,38 \\
6 & Drymaria villosa & 3,65 & 3,42 \\
7 & Digitaria cilaris & 5,98 & 11,09 \\
8 & Eulisine indica & 21,48 & 17,13 \\
9 & Amaranthus spinonsus & 18,31 & 32,37 \\
10 & Cyperus rotundus & 19,60 & 29,57 \\
11 & Galinsoga parviflora & 61,05 & 61,36 \\
12 & Erigeron sumatrensis & 2,45 & 1,22 \\
13 & Cynodone dactilone & 8,88 & 3,36 \\
14 & Richardia brasiliensis & 0,76 & 7,86 \\
15 & Oxalis corniculata & 2,37 & 0,71 \\
16 & Leptochloa chinensis & 0,41 & 1,97 \\
\hline
\end{tabular}

Berat kering tanaman merupakan gambaran translokasi fotosintat ke seluruh bagian tanaman, sehingga laju tumbuh tanaman sangat ditentukan oleh laju fotosintesis yang maksimal. Laju tumbuh tanaman dapat dipengaruhi pula oleh suhu dan kelembaban. Prawiranata $d k k$ (1981) menyatakan bahwa berat kering tanaman mencerminkan nitrisi tanaman karena berat kering tersebut tergantung pada fotosintesis. Pertumbuhan dan pembentukan organ vegetatif tanaman berpengaruh terhadap berat kering. Proses ini sangat dipengaruhi oleh ketersediaan unsur hara bagi tanaman serta laju fotosintesis. Semakin banyak energi cahaya matahari yang di konversi pada proses fotosintesis menjadi fotosintat, maka bobot kering total tanaman akan semakin banyak.

\section{Koefesien Komunitas Populasi Gulma}

Data pada Tabel 4 terlihat bahwa nilai koefisien komunitas pada areal tomat perbandingan antara lokasi pengamatan di 4 desa pada Kecamatan Cisurupan dan Kecamatan Pasirwangi menunjukkan secara umum nilai C dibawah $75 \%$. Hal ini menunjukkan bahwa di Kecamatan Cisurupan dan Kecamatan Pasirwangi memiliki tingkat perbedaan jenis gulma yang cukup besar. Perbedaan jenis gulma ini karena spesies gulma yang tumbuh di Kecamatan Cisurupan tidak semua tumbuh juga di Kecamatan Pasirwangi begitupun sebaliknya. Adanya tingkat perbedaan populasi yang kecil karena keadaan lingkungan di Kecamatan Cisurupan dan Kecamatan 
Pasirwangi yang sedikit berbeda. Perbedaan spesies gulma disebabkan cara budidaya yang berbeda sehingga memberikan respon yang berbeda. Hal ini menunjukkan bahwa di Kecamatan Cisurupan dan Kecamatan Pasirwangi memiliki kesamaan populasi yang cukup besar.

\section{Tabel 4. Nilai Koefisien Komunitas Gulma pada Pertanaman Tomat di} Kabupaten Garut

\begin{tabular}{ccc}
\hline \multirow{2}{*}{ No } & \multicolumn{2}{c}{ Tomat } \\
\cline { 2 - 3 } & Area Penelitian & $\mathrm{C}(\%)$ \\
\hline 1. & $1: 2$ & $60,63 \%$ \\
2. & $1: 3$ & $73,95 \%$ \\
3. & $1: 4$ & $69,76 \%$ \\
4. & $2: 3$ & $57,93 \%$ \\
5. & $2: 4$ & $53,52 \%$ \\
6. & $3: 4$ & $79,66 \%$ \\
\hline
\end{tabular}

Keterangan : 1 = Desa Cisurupan. 2 = Desa Kramatwangi, 3 = Desa Padaawas, dan 4= Desa Barusari

Menurut Tjitrosoedirdjo (1984), bila nilai C lebih besar dari 75\% maka diantara kedua areal tersebut terdapat kesamaan populasi yang cukup besar dan bila nilai $\mathrm{C}$ lebih kecil dari $75 \%$ maka daerah tersebut tidak terdapat kesamaan populasi. Nilai koefisien komunitas populasi gulma (C) adalah nilai untuk membandingkan dua jenis vegetasi dari dua komunitas tanaman yang berbeda.

Data pada Tabel 4 menunjukkan bahwa nilai koefesien komunitas populasi di areal tomat pada satu areal percobaan nilainya diatas $75 \%$ yaitu pada daerah perbandingan 3:4. Menurut Tjitrosoedirdjo (1984), bila nilai C lebih besar dari 75\% maka diantara kedua daerah tersebut terdapat kesamaan populasi yang cukup besar. Hal ini mungkin disebabkan karena letak dari wilayah pada masing-masing areal percobaan berdekatan dan adanya kesamaan dari varietas tomat yang ditanam. Jika keadaan lingkungan mikro dari suatu habitat relatif tidak berubah, maka perubahan komposisi jenis gulma akan berjalan sangat lambat atau tidak mengalami perubahan sama sekali (Sastroutomo,1990).

\section{Indeks Keanekaragaman Spesies}

Suatu komunitas dikatakan memiliki keanekaragaman jenis yang tinggi jika komunitas itu disusun oleh banyak jenis. Sebaliknya suatu komunitas dikatakan memiliki keanekaragaman jenis yang rendah apabila komunitas tersebut disusun oleh jenis yang sedikit.

Nilai Indeks Keanekaragaman spesies (H') Shannon-Wiever dapat ditafsirkan maknanya maka digunakan kriteria menurut Barbour, Burk and Pitts (1987); Djufri (2003). Nilai H’ biasanya berkisar dari 0 sampai 7. Jika H' < 1 
kategori sangat rendah, jika H'> 1 sampai 2 kategori rendah, jika H'> 2 sampai 3 kategori sedang (medium), jika $\mathrm{H}^{\prime}>3$ sampai 4 kategori tinggi dan jika $\mathrm{H}^{\prime}>4$ kategori sangat tinggi.

Dari hasil pengamatan yang tertera pada Tabel 5 terdapat perbedaan yang cukup jelas antara kisaran nilai yang ada pada beberapa lokasi pengamatan. Pada setiap desa masing-masing pengamatan areal tomat menunjukkan nilai yang hampir sama. Nilai indeks keanekaragaman yang diperoleh antara 2,29 sampai 2,42, Angka tersebut menunjukkan bahwa tingkat keanekaragaman jenis di areal percobaan termasuk kategori sedang.

Tabel 5. Indeks Keanekaragaman Spesies pada Areal Tomat di Kabupaten Garut

\begin{tabular}{|c|c|c|c|c|c|}
\hline \multirow{2}{*}{ No } & \multirow{2}{*}{ Gulma } & \multicolumn{2}{|c|}{ Kecamatan Cisurupan } & \multicolumn{2}{c|}{ Kecamatan Pasirwangi } \\
\cline { 3 - 6 } & & Ds.Cisurupan & Ds.Kramatwangi & Ds.Padaawas & Ds.Barusari \\
\hline 1 & Alteranthera sessilis & 0,21 & 0,26 & 0,17 & 0,06 \\
\hline 2 & Oxalis latifolia & 0,17 & 0,36 & 0,20 & 0,20 \\
\hline 3 & Portulaca oleraceae & 0,17 & 0,04 & 0,14 & 0,14 \\
\hline 4 & Erechhites valerianifolia & 0,08 & 0,09 & 0,10 & 0,09 \\
\hline 5 & Ageratum conyzoides & & 0,14 & 0,16 & 0,13 \\
\hline 6 & Drymaria villosa & 0,14 & 0,10 & 0,09 & 0,23 \\
\hline 7 & Digitaria cilaris & 0,13 & 0,12 & 0,15 & 0,17 \\
\hline 8 & Eulisine indica & 0,28 & 0,19 & 0,30 & 0,24 \\
\hline 9 & Amaranthus spinonsus & 0,18 & 0,17 & 0,23 & 0,22 \\
\hline 10 & Cyperus rotundus & 0,21 & 0,08 & 0,15 & 0,22 \\
\hline 11 & Galinsoga parviflora & 0,32 & 0,27 & 0,35 & 0,34 \\
\hline 12 & Erigeron sumatrensis & 0,14 & 0,08 & 0,06 & \\
\hline 13 & Cynodone dactilone & 0,26 & 0,14 & 0,08 & 0,05 \\
\hline 14 & Richardia brasiliensis & & 0,04 & 0,04 & 0,14 \\
\hline 15 & Oxalis corniculata & 0,13 & 0,13 & 0,07 & 0,08 \\
\hline 16 & Leptochloa chinensis & & 0,06 & & 0,13 \\
\hline & total & 2,40 & 2,29 & 2,31 & 2,42 \\
\hline
\end{tabular}

\section{KESIMPULAN}

Spesies gulma pada tanaman tomat ada 16 spesies yang terdiri dari 11 spesies gulma daun lebar, 4 spesies gulma rumput, dan 1 spesies gulma teki. Dari 16 spesies gulma pada tanaman tomat di Kecamatan Cisurupan tercatat spesies gulma yang dominan dari jenis gulma daun lebar, yaitu: Galinsoga parviflora $(16,49 \%)$ dan Oxalis latifolia $(16,14 \%)$, di Kecamatan Pasirwangi gulma yang dominan yaitu gulma daun lebar Galinsoga parviflora (25,62\%). Keanekaragaman spesies ini disebabkan oleh pola tanam serta pengendalian gulma yang beda.

Nilai koefisien komunitas pada areal tomat perbandingan antara Kecamatan Cisurupan dan Kecamatan Pasirwangi menunjukkan nilai C sebesar 73,45\%. Hal 
ini menunjukkan bahwa di Kecamatan Cisurupan dan Kecamatan Pasirwangi memiliki tingkat perbedaan jenis gulma yang cukup besar.

\section{DAFTAR PUSTAKA}

Aldrich, R.J. and R.J. Kremer. 1997. Principles in Weed Management. Second Edition. Iowa State University Press, Ames Iowa

Mahfudz. 2005. Dinamika Infestasi dan Karakter Ekofisiologi Gulma di Daerah Penyangga Taman Nasional Lore Lindu. Disertasi. Sekolah Pascasarjana Institut Pertanian Bogor. Bogor.

Nasution, U. 1981. Inventarisasi Gulma di Perkebunan Karet Sumatera Utara dan Hubungannya dengan Pengelolaan Gulma. Pros. Kongres Ke-6 Himpunan Ilmu Gulma Indonesia. Medan

Nietto, J.H., M.A. Brondo, and T.J. Gonzales. 1968. Critical Period of Crop Growth Cycle for Competition From Weed. PANS (C) 14: 159-166.

Prawiranata, W., S. Harran dan P. Tjondronegoro. 1981. Dasar-Dasar Fisiologi Tumbuhan Jilid I. Departemen Botani Fakultas Pertanian Institut Pertanian Bogor Reader dan Buck. 2000. Pertumbuhan Gulma pada Kondisi Lingkungan. PT. Gramedia Press, Jakarta.

Sastroutomo, SS. 1990. Ekologi Gulma. PT. Gramedia Pustaka Utama. Jakarta Soerianegara, I dan Andry Indrawan. 2005. Ekologi Hutan Indonesia. Fakultas Kehutanan Institut Pertanian Bogor.

Tjitreosoedirdjo, JW. dan IH. Utomo. 1984. Pengelolaan Gulma di Perkebunan. PT. Gramedia. Jakarta. 